\title{
Does environmental Kuznets curve hypothesis exist? evidence from dynamic panel threshold
}

\begin{abstract}
Carbon dioxide $\left(\mathrm{CO}_{2}\right)$ emissions have been rising globally and have raised public concern regarding their detrimental effects to human life. This article investigates the validity of the Environmental Kuznets Curve (EKC) hypothesis in developing countries in a nonlinear framework. The article applies the dynamic panel threshold method, which is able to estimate the EKC turning point. The main findings reveal the existence of a nonlinear relationship between income (GDP per capita) and carbon dioxide emissions. Precisely, for developing countries (low and middle income) the results reveal that GDP per capita is positive and significantly related to $\mathrm{CO}_{2}$ emissions, below and above the threshold. These results challenge the validity of the EKC hypothesis in developing countries, suggesting that developing countries are still below the desired income turning point, at which better economic development will lead to reduced environmental damage. Based on the study findings, it may be inappropriate for the policymakers in developing countries to adopt the EKC postulate as the theoretical basis for policies favouring economic growth.
\end{abstract}

Keyword: CO2 emissions; Environmental Kuznets curve; Economic growth; Dynamic panel threshold 